\title{
Incidence and potential mechanism of resolved, persistent and newly acquired malapposition three days after implantation of self-expanding or balloon-expandable stents in a STEMI population: insights from optical coherence tomography in the APPOSITION II study
}

Shimpei Nakatani ${ }^{1}, \mathrm{MD}$; Yoshinobu Onuma ${ }^{1}, \mathrm{MD}, \mathrm{PhD}$; Yuki Ishibashi ${ }^{1}, \mathrm{MD}, \mathrm{PhD}$; Antonios Karanasos ${ }^{1}, \mathrm{MD}$; Evelyn Regar ${ }^{1}, \mathrm{MD}$, PhD; Hector M. Garcia-Garcia², MD, PhD; Corrado Tamburino3 ${ }^{3}$ MD, PhD; Jean Fajadet ${ }^{4}, \mathrm{MD}$; Mathias Vrolix ${ }^{5}$, MD; Bernhard Witzenbichler ${ }^{6}, \mathrm{MD}$; Eric Eeckhout ${ }^{7}, \mathrm{MD}, \mathrm{PhD}$; Christian Spaulding 8,9 , MD, PhD; Krzysztof Reczuch ${ }^{10}$, MD, PhD; Alessio La Manna ${ }^{3}$, MD; René Spaargaren ${ }^{11}, \mathrm{MD}$; Davide Capodanno ${ }^{3}, \mathrm{MD}$; Glenn Van Langenhove ${ }^{12}, \mathrm{MD}, \mathrm{PhD}$; Stefan Verheye ${ }^{12}$, MD, PhD; Patrick W. Serruys ${ }^{13}$, MD, PhD; Robert-Jan van Geuns ${ }^{1 *}$, MD, PhD

1. Thoraxcenter, Erasmus Medical Center, Rotterdam, The Netherlands; 2. Cardialysis, Rotterdam, The Netherlands; 3. Division of Cardiology, Ferrarotto Hospital, University of Catania, Catania, Italy; 4. Department of Interventional Cardiology, Clinique Pasteur, Toulouse, France; 5. Department of Cardiology, Ziekenhuis Oost-Limburg, Genk, Belgium; 6. Department of Cardiology, Charité Campus Benjamin Franklin, Berlin, Germany; 7. Cardiology Service, Centre Hospitalier Universitaire Vaudois, Lausanne, Switzerland; 8. Hôpital Européen Georges Pompidou, Assistance Publique Hôpitaux de Paris, Paris Descartes University, Paris, France; 9. Institut National de la Santé et de la Recherche Médicale Unité 970, Paris, France; 10. Military Hospital, Wrocław, Poland; 11. STENTYS SA, Paris, France; 12. Department of Cardiology, Antwerp Cardiovascular Center, ZNA Middelheim, Antwerp, Belgium; 13. International Centre for Circulatory Health, NHLI, Imperial College London, London, United Kingdom GUEST EDITOR: Fernando Alfonso, MD; Cardiac Department, Hospital Universitario de la Princesa, IIS-IP Universidad Autonoma de Madrid, Madrid, Spain

This paper also includes supplementary data published online at: http://www.pcronline.com/eurointervention/91st_issue/179

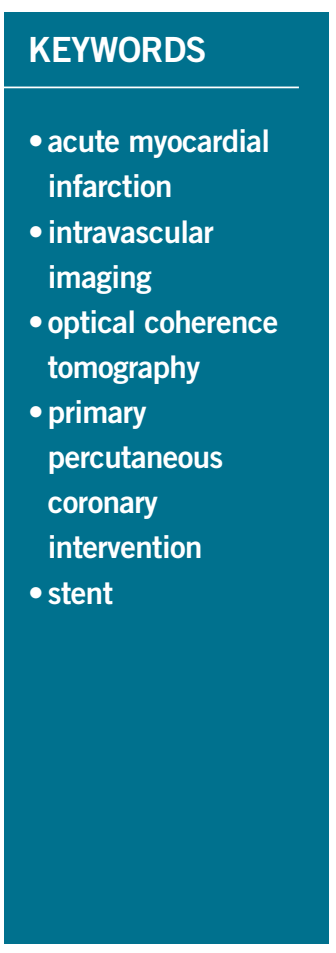

\section{Abstract}

Aims: The aim of the current study was to investigate the frequency and mechanisms of sequential incomplete stent apposition (ISA) changes such as persistent, resolved or newly acquired ISA during the first three days after primary PCI (pPCI) in a matched segment-level analysis, with the comparison between self-expanding and balloon-expandable stents assessed by optical coherence tomography (OCT).

Methods and results: The current analysis is a substudy of the APPOSITION II study that included 69 patients (self-expanding: 35, balloon-expandable: 34 ) using serial optical coherence tomography (OCT) post procedure and three days after pPCI. In order to evaluate a temporal change in ISA, stented regions were segmented using fiduciary landmarks. In a total of 228 corresponding segments, persistent and newly acquired ISA were less frequently observed in self-expanding stents than in balloon-expandable stents $(11.5 \%$ vs. $33.9 \%, \mathrm{p}<0.01,2.7 \%$ vs. $14.8 \%, \mathrm{p}<0.01$, respectively). New appearances of ISA were caused by tissue resorption, vasorelaxation and "early" recoil in balloon-expandable stents, and only tissue resorption in self-expanding stents.

Conclusions: Three days after pPCI, tissue resorption and vasorelaxation were biological factors associated with new appearance of ISA while "early" recoil of balloon-expandable stents was a mechanical factor. Both persistent ISA and newly acquired ISA occurred less frequently in self-expanding stents, resulting in a low number of ISA segments compared to balloon-expandable stents. Clinical Trials Registration Information: Randomised Comparison Between the STENTYS Self-expanding Coronary Stent and a Balloon-expandable Stent in Acute Myocardial Infarction (APPOSITION II). ClinicalTrials.gov Identifier: NCT01008085

*Corresponding author: Thoraxcenter, Erasmus MC, 's Gravendijkwal 230, 3015 CE Rotterdam, The Netherlands. E-mail: rvangeuns@erasmusmc.nl 


\section{Abbreviations}

ACS acute coronary syndrome

BMS bare metal stent

DES drug-eluting stent

ISA incomplete stent apposition

OCT optical coherence tomography

pPCI primary percutaneous coronary intervention

QCA quantitative coronary angiography

STEMI ST-elevation myocardial infarction

\section{Introduction}

Primary percutaneous coronary intervention (pPCI) is considered to be the optimal approach for the treatment of ST-elevation myocardial infarction (STEMI) due to its superior reperfusion outcome when compared to thrombolysis ${ }^{1}$.

Optimal stent deployment in pPCI remains challenging due to the presence of thrombus and vasoconstriction. In the setting of STEMI, a rupture or erosion of vulnerable plaques initiates a series of inflammatory reactions and formation of thrombus. In addition, catecholamine stimulation, inflammatory substances, and the impairment of microcirculation contribute to vasoconstriction ${ }^{2,3}$. At the time of pPCI, this situation could lead to an underestimation of the vessel size and result in underdeployment of stents ${ }^{4}$. A few days after pPCI, the interaction of the struts with the vessel wall can alter dynamically due to vessel condition and/or mechanical changes of devices, for instance: i) disappearance of thrombus trapped between the stent struts and vessel wall, ii) vasorelaxation of initially vasoconstricted vessels, iii) additional formation of thrombus due to stent strut penetration into the necrotic core, iv) stent recoil in balloon-expandable stents or stent enlargement in self-expanding stents. These alterations could subsequently result in the disappearance or the new acquisition of incomplete stent apposition (ISA).

Recently, Nakano et al demonstrated, in an autopsy series of patients who died after receiving bare metal stents (BMS, 49\%) or drug-eluting stents (DES, $51 \%$ ) in a setting of acute coronary syndrome (ACS), that the presence of ISA was one of the primary indicators of early stent thrombosis. Previous studies have demonstrated the dramatic alterations of ISA within three days after pPCI in lesion/patient level analysis. The persistence or disappearance of acute ISA at three days is presumably an important factor related to the occurrence of early stent thrombosis. However, the sequential local changes of ISA and the factors that could influence the temporal evolution of ISA have not been characterised. To enable the assessment of local changes of ISA, the matching of the segments at follow-up by fiduciary landmarks is mandatory with the finest level of matching possible (segment-level analysis) ${ }^{5,6}$.

Editorial, see page 852

Against this background, the aim of the current study was to investigate the frequency and mechanisms of sequential ISA changes such as persistent, resolved or newly acquired ISA during the first three days after pPCI in a matched segment-level analysis with the comparison between self-expanding and balloon-expandable stents assessed by optical coherence tomography (OCT).

\section{Methods STUDY POPULATION}

The APPOSITION II study is a randomised, international, multicentre, open-label clinical study with blinded assessment of the study endpoints for comparison between self-expanding stents and balloon-expandable stents in the setting of STEMI, with OCT examinations performed both immediately and three days after stent implantation ${ }^{7}$. The study population consisted of patients admitted for STEMI with onset of symptoms $<12$ hours. The patients who met the study selection criteria were randomly assigned 1:1 to receive treatment with a self-expanding stent (STENTYS SA, Paris, France) or a balloon-expandable stent (MULTI-LINK VISION ${ }^{\circledR}$; Abbott Vascular, Santa Clara, CA, USA; or Driver ${ }^{\circledR}$; Medtronic, Minneapolis, MN, USA) using a computergenerated randomisation scheme. Angiographic and OCT assessments were performed immediately after stent implantation and three days after the procedure. The details of the trial are described elsewhere. The study complied with the Declaration of Helsinki. Local institutional ethics committees approved the study protocol and all participating patients provided informed consent.

\section{ANGIOGRAPHIC ASSESSMENT}

In the calculation of percent diameter stenosis $(\% \mathrm{DS})$, the reference diameter was calculated using the automatic interpolation of the diameter curve at the site of the minimal lumen diameter ${ }^{8}$. For the assessment of vasoconstriction/relaxation, the mean lumen diameter of the remote distal segment (5 to $20 \mathrm{~mm}$ distal to the stented segment) was measured using quantitative coronary angiography analysis (QCA) ${ }^{9}$. Details of the methods for QCA are described in the Online Appendix.

\section{QUANTITATIVE ANALYSIS ON OCT}

OCT acquisition was executed with the C7 XR Fourier-Domain System (LightLab Imaging, Westford, MA, USA) using the flushing technique. The automated pullback speed was $20 \mathrm{~mm} / \mathrm{s}$ and the frame rate was 100 images/s. The OCT measurements were performed at $1 \mathrm{~mm}$ longitudinal intervals or at intervals of 200 microns (ISA analysis) with the QCU-CMS software (Medis medical imaging systems bv, Leiden, The Netherlands). Details of the analysis methods have been previously described ${ }^{7,10}$ (Online Appendix).

\section{ISA ANALYSIS ON OCT}

Apposition of struts was assessed strut by strut by measuring the distance between the adluminal reflective border of a strut and the lumen contour ${ }^{7}$. If this distance was longer than the strut thickness, it was considered as an ISA strut. The thickness of the STENTYS stent is $112 \mu \mathrm{m}$ for the small and $146 \mu \mathrm{m}$ for the medium and large sizes; the strut thickness for the VISION and Driver stents is 84 and $100 \mu \mathrm{m}$, respectively. Struts crossing over the ostium of side branches and overlapping stents were excluded from the analysis of apposition.

Whenever any malapposed strut was detected in the initial $1 \mathrm{~mm}$ interval analysis, an all-frame analysis $(200 \mu \mathrm{m})$ was performed in 
adjacent cross-sections with ISA to calculate the following ISA parameters: 1) maximum ISA detachment distance, 2) maximum ISA area, and 3) ISA volume in the segment. The ISA detachment distance was defined as the distance between the adluminal leading edge of the strut and vessel wall minus the strut thickness at malapposed struts ${ }^{5,11}$. The ISA area was defined as the space between the lumen contour and stent contour at the location of malapposed struts, which was drawn manually ${ }^{7}$. The ISA volumes were computed by a disc summation method ${ }^{12}$.

To summarise the spatial distribution of the malapposed struts along the stents, three "foldout views" were created by correlating the longitudinal distance from the distal edge of the stent to the strut (abscissas) with the angle in which the struts were located in the circular cross-section with respect to the centre of gravity of the vessel (ordinates) ${ }^{13,14}$. In addition, malapposed struts were colour-coded according to the ISA detachment distance. The resulting graphic represented the stented vessel, as if it had been cut longitudinally along the reference angle $0^{\circ}$ and spread out on a flat surface (Figure 1).

\section{SEQUENTIAL SEGMENTAL ANALYSIS IN STENTED REGION}

The stented regions were segmented by using fiduciary landmarks such as a side branch or overlapping part, which enables the assessment of the sequential change of stented segments (segmental analysis) (Figure 2A). The stented segments were classified into four groups: resolved, persistent, newly acquired ISA and no ISA (Figure 2B). A resolved ISA is a post-procedural ISA that resolves at three-day follow-up. A persistent ISA is a post-procedural ISA that remains present at three days. A newly acquired ISA is a newly developed ISA that is identified at three days despite complete stent apposition during the initial procedure. A no ISA was a segment without malapposed struts post procedure and at three days.

\section{DEFINITION OF VESSEL/LUMEN CHANGE AND MECHANICAL CHANGE OF A STENT}

Mechanical change of a stent, stent recoil and enlargement were defined by the sequential difference of mean stent area in corresponding segments. According to the range of reproducibility measurements between inter-/intra-observer and inter-scan ${ }^{15,16}$, Tanimoto et al reported that the standard deviation of absolute interobserver difference in the stent area analysis was $0.68 \mathrm{~mm}^{2}$. Jamil et al demonstrated that the $95 \%$ confidence interval of absolute inter-pullback difference in the stent area analysis was $0.9 \mathrm{~mm}^{2}$. In the current analysis, the $75 \%$ quartile of the delta in stent area analysis in balloon-expandable stents was $0.68 \mathrm{~mm}^{2}$. Therefore, "early" stent recoil was defined as a reduction of mean stent area greater than $0.7 \mathrm{~mm}^{2}$ at three days (Figure 3A, Figure 3B), and stent enlargement was defined as an increase in mean stent area greater than $0.7 \mathrm{~mm}^{2}$ (Figure 3I, Figure 3J) ${ }^{15-18}$. Vasorelaxation was defined as an increase in mean lumen diameter greater than $5 \%$ in the remote distal segment on QCA (Figure 3C, Figure 3D) ${ }^{9}$ or a new appearance of an inter-strut dissection flap behind the struts on OCT at three days (Figure 3E, Figure 3F). When strut malapposition was resolved at three days without stent enlargement, it was considered to be due to tissue formation behind the malapposed struts (Figure 3G, Figure $\mathbf{3 H}$ ). When ISA volume increased at three-day follow-up in the absence of an "early" recoil and/or vasorelaxation, it was judged to be caused by tissue resorption (Figure 3K, Figure 3L).

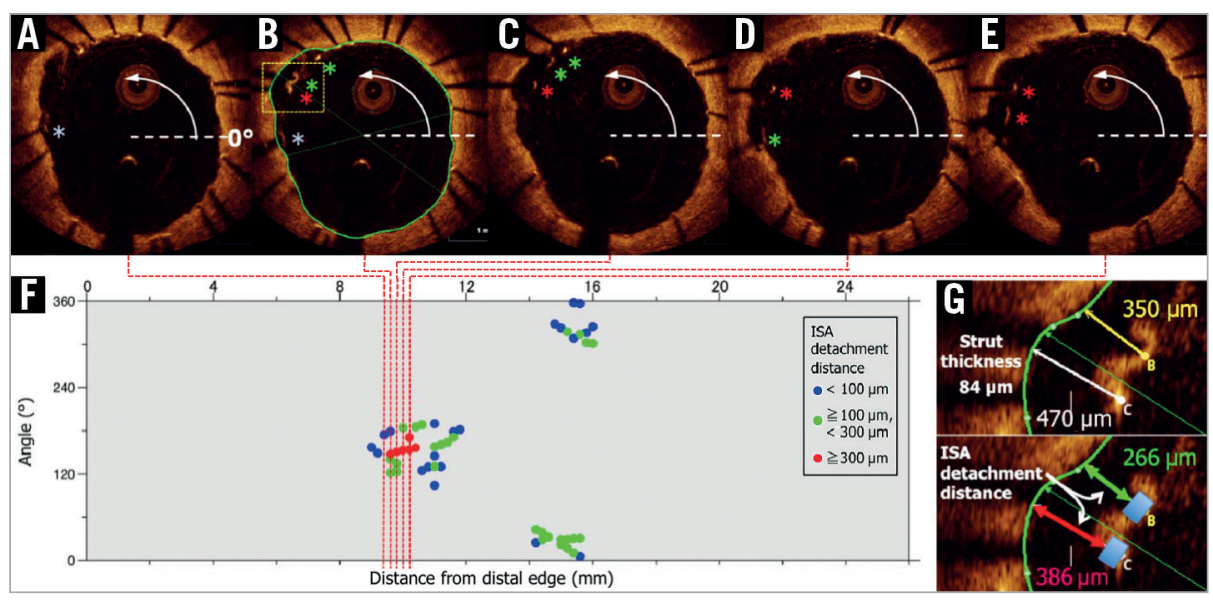

Figure 1. Foldout view with colour-coded malapposed struts. Apposition of struts was assessed strut by strut in cross-sections with 1 mm intervals. Whenever a malapposed strut was detected, an all-frame analysis (200 $\mu$ m intervals) was performed for detecting malapposed struts $(A-E)$. By taking the position at $3 o^{\prime}$ clock as the $0^{\circ}$ reference angle, the malapposed struts could be located in the circular cross-section with respect to the centre of gravity of the vessel. A foldout view of stents can be constructed by correlating the cross-sectional angular position (ordinates) with the longitudinal distance (abscissas) from the distal edge of the stent. The resultant graphic represents the stented vessel, as if it had been cut longitudinally along the reference angle $0^{\circ}$ and spread out on a flat surface $(F)$. The malapposed struts were colour-coded according to the ISA detachment distance, which was measured strut by strut, and which was defined as the distance between the adluminal parts of the strut minus the strut thickness of the malapposed strut $(G)$. 


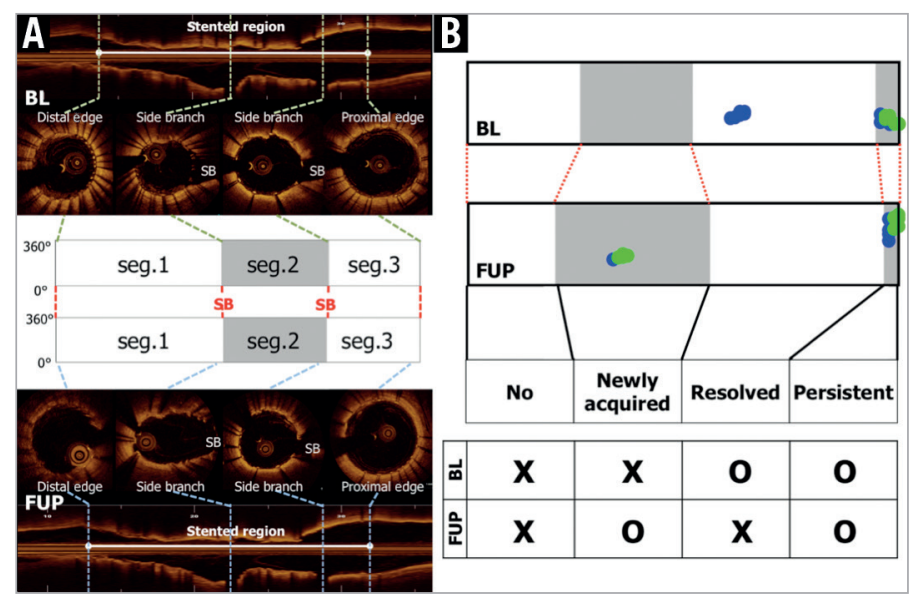

Figure 2. Segmental analysis and definitions of individual segments. The stented regions were defined as the frames between cross-sections of stent edges in which struts were detected circularly. The stented regions were segmented by using fiduciary landmarks such as side branches or overlaps (A). The corresponding segments were classified into four groups: resolved ISA is a post-procedural ISA segment that resolves at three-day follow-up, persistent ISA is a post-procedural ISA segment that remains present at the three-day follow-up, newly acquired ISA is a newly developed ISA segment that is identified at the three-day follow-up despite complete stent apposition during the initial procedure, and no ISA is a segment without malapposed struts post procedure and at three-day follow-up (B).

\section{Statistical analysis}

All statistical analyses were performed using the statistical software package SPSS, Version 21.0 (IBM Corp., Armonk, NY, USA). Normality of distributions was tested with the Kolmogorov-Smirnov test. Continuous variables are presented as the mean \pm standard deviation or median with interquartile ranges, as indicated in the Tables. Categorical variables are presented as number (\%). Comparisons between the self-expanding and balloon-expandable stents at segment level and between the persistent and resolved ISA were estimated with the Mann-Whitney U test when variables were non-normally distributed and with the Student's t-test when normally distributed. Comparisons of categorical variables were estimated with Fisher's exact test.

\section{Results}

From the 80 patients in the APPOSITION II study, 11 were excluded from this analysis because of the lack of OCT imaging data post procedure $(n=9)$ or at three-day follow-up $(n=2)$. A total of 69 lesions in 69 patients had serial OCT images (selfexpanding stents: 35, balloon-expandable stents: 34). Baseline clinical and procedural characteristics are summarised in Online Table 1. There was no significant difference between groups with respect to baseline clinical characteristics. In the selfexpanding group, post-dilation was performed more frequently than in balloon-expandable stents $(62.9 \%$ [22/35] vs. $23.5 \%$ [8/34], $p=0.001)$. The use of post-dilation was recommended if there was a residual stenosis $>30 \%$ for both treatment groups. However, there were significant differences between study sites in the frequency of post-dilatation. One site never post-dilated, whereas three other sites post-dilated in $100 \%$ of the cases in self-expanding stents. On the other hand, four sites never postdilated balloon-expandable stents.

\section{SEGMENT-LEVEL OCT ANALYSIS}

Table 1 summarises the results of OCT analysis in segmental analysis. A total of 228 segments (self-expanding stents: 113, balloonexpandable stents; 115) were assessed sequentially. Mean stent

Table 1. OCT results in segment-level analysis.

\begin{tabular}{|l|c|c|c|}
\hline & $\begin{array}{c}\text { Self-expanding } \\
(\mathbf{n}=113)\end{array}$ & $\begin{array}{c}\text { Balloon- } \\
\text { expandable } \\
(\mathbf{n}=115)\end{array}$ & p-value \\
\hline Post procedure & $7[4-10]$ & $6[3-10.5]$ & 0.24 \\
\hline Segment length, $\mathrm{mm}$ & $153[81-214]$ & $60[36.5-122.5]$ & $<0.001$ \\
\hline Analysed struts, $\mathrm{n}$ & $7.33 \pm 2.48$ & $9.00 \pm 2.25$ & $<0.001$ \\
\hline Mean stent area, $\mathrm{mm}^{2}$ & $7.73 \pm 2.57$ & $9.08 \pm 2.34$ & $<0.001$ \\
\hline Mean lumen area, $\mathrm{mm}^{2}$ & $0.06[0.01-0.22]$ & $0.23[0.12-0.48]$ & $<0.001$ \\
\hline Mean prolapse area, $\mathrm{mm}^{2}$ & $0.00[0.00-0.00]$ & $0.00[0.00-000]$ & 0.93 \\
\hline Mean isolated defect area, $\mathrm{mm}^{2}$ & $22(19.5)$ & $22(19.1)$ & 1.00 \\
\hline Isolated defect, $\mathrm{n}(\%)$ & & & \\
\hline At follow-up & $6[3-10]$ & $6[4-11]$ & 0.57 \\
\hline Segment length, $\mathrm{mm}^{2}$ & $141[75-226]$ & $65[34.5-119.5]$ & $<0.001$ \\
\hline Analysed struts, $\mathrm{n}$ & $8.53 \pm 2.53$ & $8.88 \pm 2.04$ & 0.11 \\
\hline Mean stent area, $\mathrm{mm}^{2}$ & $1.21 \pm 1.12$ & $-0.11 \pm 0.66$ & $<0.001$ \\
\hline Diff. mean stent area, $\mathrm{mm}^{2}$ & $77(68.1)$ & $0(0.0)$ & $<0.001$ \\
\hline $\begin{array}{l}\text { Stent enlargement } \\
\left.\text { (Diff. mean stent area }>0.7 \mathrm{~mm}^{2}\right), \mathrm{n}(\%)\end{array}$ & $0(0.0)$ & $28(24.3)$ & $<0.001$ \\
\hline $\begin{array}{l}\text { Stent recoil } \\
\left.\text { (Diff. mean stent area }<-0.7 \mathrm{~mm}^{2}\right), \mathrm{n}(\%)\end{array}$ & $8.62 \pm 2.58$ & $8.96 \pm 2.13$ & 0.11 \\
\hline Mean lumen area, $\mathrm{mm}^{2}$ & $0.88 \pm 1.19$ & $-0.12 \pm 0.69$ & $<0.001$ \\
\hline Diff. mean lumen area, $\mathrm{mm}^{2}$ & $0.20[0.09-0.45]$ & $0.25[0.15-0.46]$ & 0.11 \\
\hline Mean prolapse area, $\mathrm{mm}^{2}$ & $0.08[0.00-0.28]$ & $0.00[-0.14-0.11]$ & $<0.001$ \\
\hline Diff. mean prolapse area, $\mathrm{mm}^{2}$ & $0.00[0.00-0.00]$ & $0.00[0.00-0.00]$ & 0.15 \\
\hline Mean isolated defect area, $\mathrm{mm}^{2}$ & $21(18.6)$ & $14(12.2)$ & 0.02 \\
\hline Isolated defect, $\mathrm{n}(\%)$ & & & \\
\hline
\end{tabular}




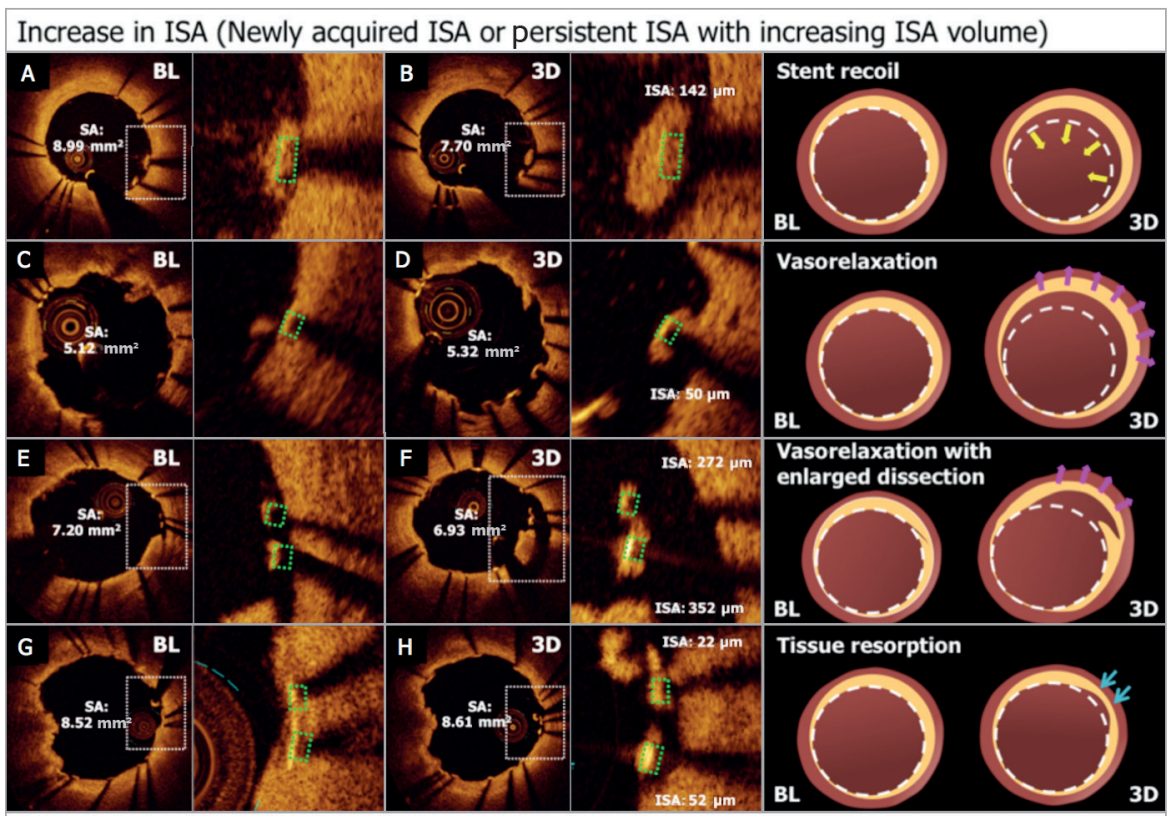

Decrease in ISA (Resolved ISA or persistent ISA with decreasing ISA volume)

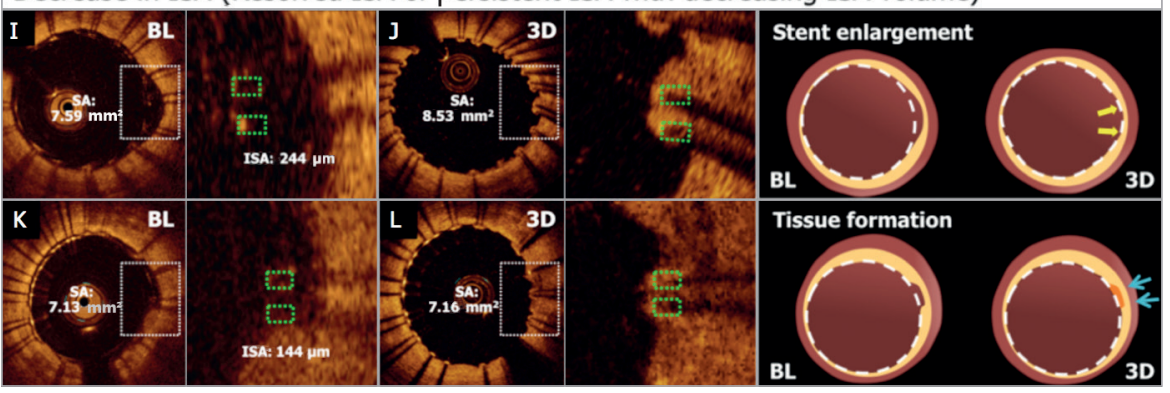

Figure 3. Mechanisms of ISA changes. The mechanisms of increase and decrease in ISA were defined by the following factors: the difference of stent area on OCT between two time points, inter-strut dissection on OCT and mean lumen diameter of remote distal segments on QCA. A) \& B) Newly acquired ISA caused by a stent recoil that is defined by the difference of mean stent area between two time points.

C) \& D) Newly acquired ISA caused by vasorelaxation that was detected on QCA by the increase of mean lumen diameter in remote distal segments. E) \& F) Newly acquired ISA caused by vasorelaxation that is defined by the enlargement of an inter-strut dissection flap behind the struts. G) \& H) Newly acquired ISA caused by tissue resorption in which stent enlargement and vasorelaxation are not observed on OCT and QCA. I) \& J) The resolved ISA caused by a stent enlargement that is defined by the difference of mean stent area between two time points. $K) \& L)$ The resolved ISA caused by tissue formation while stent enlargement is not observed.

area post procedure was $7.33 \pm 2.48 \mathrm{~mm}^{2}$ in self-expanding stents vs. $9.00 \pm 2.25 \mathrm{~mm}^{2}$ in balloon-expandable stents $(\mathrm{p}<0.001)$. Mean stent area at follow-up was $8.53 \pm 2.53 \mathrm{~mm}^{2}$ in self-expanding stents vs. $8.88 \pm 2.04 \mathrm{~mm}^{2}$ in balloon-expandable stents $(\mathrm{p}=0.11)$. For the self-expanding stent, the mean stent area was significantly enlarged at three days - by $1.21 \pm 1.12 \mathrm{~mm}^{2}(\mathrm{p}<0.01)$. For the balloon-expandable stent, the mean stent area had a tendency to decrease at three-day follow-up - by $0.11 \pm 0.66 \mathrm{~mm}^{2}(\mathrm{p}=0.07)$. The difference between mean stent area post procedure and at threeday follow-up was significantly larger in self-expanding stents than in balloon-expandable stents $\left(1.21 \pm 1.12 \mathrm{~mm}^{2}\right.$ vs. $-0.11 \pm 0.66$ $\left.\mathrm{mm}^{2}, \mathrm{p}<0.001\right)$. Although the stent area of a self-expanding stent was smaller than that of a balloon-expandable stent immediately post procedure, there was no difference between the two stents at three days.

\section{SEGMENT-LEVEL ISA ANALYSIS}

Table 2 summarises the ISA parameters in segmental analysis, and the foldout views depict the clustering and spread distribution of ISA (Figure 4). ISA segments were more frequently observed in balloon-expandable stents than in self-expanding stents both post procedure and at three days (post procedure: $24.8 \%$ vs. $44.3 \%$, $\mathrm{p}=0.002$; at three days: $14.2 \%$ vs. $48.7 \%, \mathrm{p}<0.001)$. Although there was a significant difference in the ISA length and maximum ISA detachment distance, the maximum ISA area and ISA volume were similar between the two groups post procedure. At three days, ISA parameters in the balloon-expandable stents were significantly larger than in the self-expanding stents (Table 2).

In sequential assessment, the incidence of resolved ISA was similar in the self-expanding stents and the balloon-expandable stents (self-expanding: $13.3 \%$, balloon-expandable; $10.4 \%, \mathrm{p}=0.51$ ) 
Table 2. Segment-level ISA analysis.

\begin{tabular}{|c|c|c|c|}
\hline & $\begin{array}{c}\text { Self-expanding } \\
\quad(n=113)\end{array}$ & $\begin{array}{c}\text { Balloon- } \\
\text { expandable } \\
(n=115)\end{array}$ & $p$-value \\
\hline \multicolumn{4}{|l|}{ Post procedure } \\
\hline ISA segment, n (\%) & $28(24.8)$ & $51(44.3)$ & 0.002 \\
\hline ISA length, mm² & $0.9[0.6-1.5]$ & $1.1[0.8-2.3]$ & 0.02 \\
\hline Max ISA length, $\mathrm{mm}^{2}$ & $0.6[0.5-1.2]$ & $1.0[0.8-2.3]$ & 0.005 \\
\hline Max ISA detachment distance, $\mu \mathrm{m}$ & 86 [56-205] & 162 [106-293] & 0.03 \\
\hline Max ISA area, mm² & $0.36[0.17-0.57]$ & $0.35[0.20-0.91]$ & 0.34 \\
\hline ISA volume, $\mathrm{mm}^{3}$ & $0.23[0.10-0.44]$ & $0.25[0.11-1.33]$ & 0.17 \\
\hline Malapposed struts $>5 \%, \mathrm{n}(\%)^{\pi}$ & $9(8.0)$ & $27(23.5)$ & 0.002 \\
\hline Malapposed struts $>30 \%, \mathrm{n}(\%)^{\pi}$ & $0(0.0)$ & $6(5.3)$ & 0.03 \\
\hline \multicolumn{4}{|l|}{ 3-day follow-up } \\
\hline ISA segment, $n(\%)$ & $16(14.2)$ & $56(48.7)$ & $<0.001$ \\
\hline ISA length, mm & $0.7[0.4-1.0]$ & $1.2[0.7-2.8]$ & 0.002 \\
\hline Max ISA length, mm & $0.6[0.4-0.9]$ & $1.0[0.6-2.0]$ & 0.01 \\
\hline Max ISA detachment distance, $\mu \mathrm{m}$ & 153 [79-238] & 280 [144-396] & 0.01 \\
\hline Max ISA area, $\mathrm{mm}^{2}$ & $0.42[0.20-0.66]$ & $0.60[0.28-0.98]$ & 0.01 \\
\hline ISA volume, $\mathrm{mm}^{3}$ & $0.20[0.07-0.37]$ & $0.47[0.19-1.71]$ & 0.01 \\
\hline Malapposed struts $>5 \%, \mathrm{n}(\%)^{\pi}$ & $6(5.3)$ & $32(27.8)$ & $<0.001$ \\
\hline Malapposed struts $>30 \%, n(\%)^{\pi}$ & $0(0.0)$ & $4(3.5)$ & 0.12 \\
\hline \multicolumn{4}{|l|}{ Sequential assessment } \\
\hline Resolved, n (\%) & $15(13.3)$ & $12(10.4)$ & 0.51 \\
\hline Persistent, n (\%) & $13(11.5)$ & $39(33.9)$ & $<0.001$ \\
\hline Newly acquired, n (\%) & $3(2.7)$ & $17(14.8)$ & 0.001 \\
\hline № ISA, n (\%) & $82(72.6)$ & $47(40.9)$ & $<0.001$ \\
\hline
\end{tabular}

(Table 2, Figure 5). The incidence of persistent and newly acquired ISA in self-expanding stents was significantly lower than in balloon-expandable stents (persistent: $11.5 \%$ vs. $33.9 \%, \mathrm{p}<0.001$; newly acquired: $2.7 \%$ vs. $14.8 \%, p=0.001$ ) (Table 2, Figure 5). In self-expanding stents, $53.6 \%$ (15/28) of the post-procedural ISA was resolved and 46.4\% (13/28) was persistent. In balloon-expandable stents, $23.5 \%(12 / 51)$ of post-procedural ISA was resolved and $76.5 \%$ (39/51) was persistent (Table 2, Figure 5).

\section{POST-PROCEDURAL ISA SIZE AND PERSISTENCY OR DISAPPEARANCE OF ISA AT THREE DAYS}

When comparing post-procedural ISA parameters in persistent and resolved ISA, there was no significant difference in the ISA parameters in self-expanding stents (Online Table 2). In balloon-expandable stents, the maximum ISA detachment distance of persistent ISA was higher than that of resolved ISA (persistent: $237 \mu \mathrm{m}$, resolved: $105 \mu \mathrm{m}, \mathrm{p}=0.01$ ). Table 3 shows an estimation of the likelihood at three-day follow-up of resolved versus persistent ISA according to the ISA parameters post procedure. In self-expanding stents, the maximum ISA detachment distance $\geq 250 \mu \mathrm{m}$, the maximum ISA area $\geq 1.0 \mathrm{~mm}^{2}$ and ISA volume $\geq 0.7 \mathrm{~mm}^{3}$ post procedure resulted in persisting ISA in all cases. In balloon-expandable stents, the maximum ISA detachment distance $\geq 200 \mu \mathrm{m}$, the
Table 3. Likelihood of persistent versus resolved ISA at three-day follow-up.

\begin{tabular}{|c|c|c|c|c|}
\hline \multirow{2}{*}{} & \multicolumn{2}{|c|}{ Self-expanding } & \multicolumn{2}{c|}{ Balloon-expandable } \\
\cline { 2 - 5 } & Persistent & Resolved & Persistent & Resolved \\
\hline Max ISA detachment distance, $\mu \mathrm{m}$ \\
\hline$<100$ & $\ldots$ & 73.3 & $\ldots$ & 54.5 \\
\hline$<150$ & $\ldots$ & 70.6 & $\ldots$ & 41.7 \\
\hline$<200$ & $\ldots$ & 61.9 & $\ldots$ & 40.0 \\
\hline$<250$ & $\ldots$ & 65.2 & $\ldots$ & 33.3 \\
\hline$\geq 100$ & 69.2 & $\ldots$ & 85.0 & $\ldots$ \\
\hline$\geq 150$ & 72.7 & $\ldots$ & 92.6 & $\ldots$ \\
\hline$\geq 200$ & 71.4 & $\ldots$ & 100.0 & $\ldots$ \\
\hline$\geq 250$ & 100.0 & $\ldots$ & 100.0 & $\ldots$ \\
\hline
\end{tabular}

\section{Max ISA area, $\mathrm{mm}^{2}$}

\begin{tabular}{|c|c|c|c|c|}
\hline$<0.3$ & $\ldots$ & 76.9 & $\ldots$ & 39.1 \\
\hline$<0.5$ & $\ldots$ & 63.2 & $\ldots$ & 31.0 \\
\hline$<0.7$ & $\ldots$ & 60.0 & $\ldots$ & 29.4 \\
\hline$<1.0$ & $\ldots$ & 55.6 & $\ldots$ & 29.3 \\
\hline$\geq 0.3$ & 66.7 & $\ldots$ & 89.3 & $\ldots$ \\
\hline$\geq 0.5$ & 66.7 & $\ldots$ & 86.4 & $\ldots$ \\
\hline$\geq 0.7$ & 100.0 & $\ldots$ & 88.2 & $\ldots$ \\
\hline$\geq 1.0$ & 100.0 & $\ldots$ & 100.0 & $\ldots$ \\
\hline
\end{tabular}

ISA volume, $\mathrm{mm}^{3}$

\begin{tabular}{|c|c|c|c|c|}
\hline$<0.1$ & $\ldots$ & 71.4 & $\ldots$ & 50.0 \\
\hline$<0.3$ & $\ldots$ & 58.8 & $\ldots$ & 37.0 \\
\hline$<0.5$ & $\ldots$ & 59.1 & $\ldots$ & 36.4 \\
\hline$<0.7$ & $\ldots$ & 55.6 & $\ldots$ & 34.3 \\
\hline$\geq 0.1$ & 52.4 & $\ldots$ & 84.6 & $\ldots$ \\
\hline$\geq 0.3$ & 54.5 & $\ldots$ & 91.7 & $\ldots$ \\
\hline$\geq 0.5$ & 66.7 & $\ldots$ & 100.0 & $\ldots$ \\
\hline$\geq 0.7$ & 100.0 & $\ldots$ & 100.0 & $\ldots$ \\
\hline
\end{tabular}

maximum ISA area $\geq 1.0 \mathrm{~mm}^{2}$ and ISA volume $\geq 0.5 \mathrm{~mm}^{3}$ post procedure resulted in persisting ISA in all cases.

\section{MECHANISMS OF ISA CHANGE}

On QCA, the frequency of vasorelaxation was similar between the two groups (self-expanding: 11 vessels [32.4\%], balloon-expandable: 11 vessels [31.4\%], p=1.00) (Online Table 3). On OCT, stent recoil was observed in $24.3 \%$ of balloon-expandable stent segments and stent enlargement was observed in $68.1 \%$ of selfexpanding stent segments.

The resolved ISA and persistent ISA with decreasing ISA volume caused by stent enlargement were observed only in selfexpanding stents (11 segments [9.7\%] in resolved ISA, six segments [5.3\%] in persistent ISA with decreasing ISA volume). The persistent ISA with decreasing ISA volume caused by tissue formation was observed less frequently in self-expanding stents than in balloon-expandable stents (self-expanding: two segments [1.8\%], balloon-expandable: 13 segments [11.3\%], $\mathrm{p}=0.01$ ) (Table 4, Online Figure 1). 


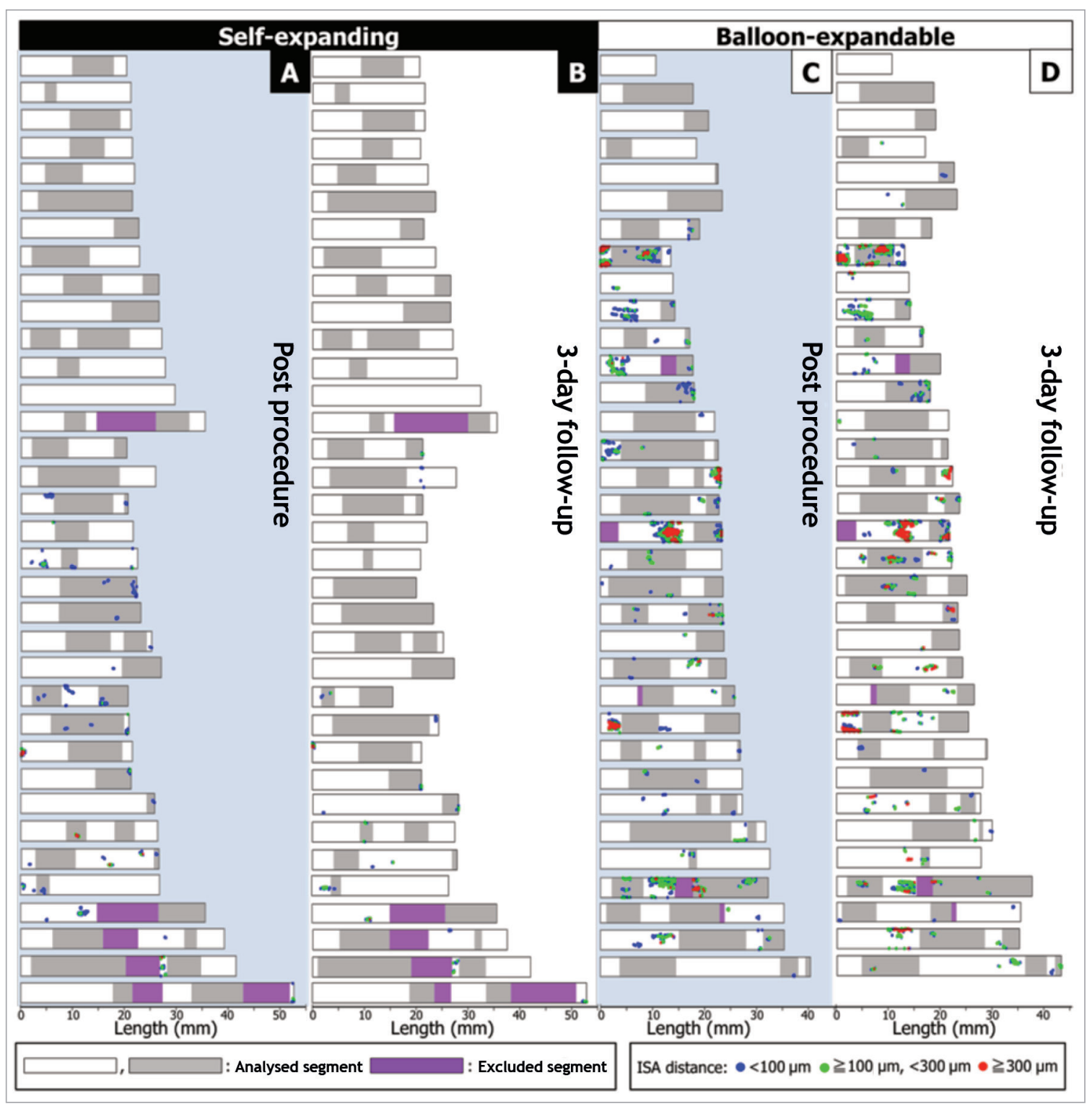

Figure 4. Sequential foldout views of 228 segments. Foldout views based on frame-by-frame analysis show malapposed struts in 228 segments post procedure and three days after pPCI. The foldout view allows depiction and comparison of the clustering and spread distribution of ISA at two time points. A) \& C) Post procedure (A: self-expanding; C: balloon-expandable). B) \& D) Three days after pPCI (B: self-expanding; $D$ : balloon-expandable). The blue dots illustrate the malapposed struts with ISA detachment distance $<100$ microns, the green dots with ISA detachment distance $\geq 100$ microns, and $<300$ microns, the red dots with ISA detachment distance $\geq 300$ microns. ISA: incomplete stent apposition

The newly acquired ISA and persistent ISA with increasing ISA volume caused by "early" recoil were observed only in balloonexpandable stents (five segments [4.3\%] in newly acquired ISA, six segments [5.2\%] in persistent ISA with increasing ISA volume). The persistent ISA with increasing ISA volume caused by tissue resorption was less frequently observed in self-expanding stents than in balloon-expandable stents (two segments [37.4\%] vs. 11 segments [7.1\%], $\mathrm{p}=0.02$ ) (Table 4, Online Figure 1).

\section{Discussion}

To evaluate the temporal change of ISA and its mechanism, we conducted a matched segment-level analysis and additional QCA analysis with the comparison between self-expanding and balloon-expandable stents assessed by OCT using data from the APPOSITION II study. The main findings of the current analysis are the following. 1) Three days after pPCI in the segmental analysis, persistent and newly acquired ISA segments were less frequently observed in selfexpanding stents than in balloon-expandable stents (persistent: $11.5 \%$ vs. $33.9 \%, \mathrm{p}<0.001$; newly acquired: $2.7 \%$ vs. $14.8 \%, \mathrm{p}=0.001)$. 2) The newly acquired ISA in balloon-expandable stents were caused by tissue resorption, vasorelaxation and "early" recoil while in selfexpanding stents it was caused by tissue resorption. 3) Resolved ISA was caused by stent enlargement in self-expanding stents while tissue formation was responsible in balloon-expandable stents. 


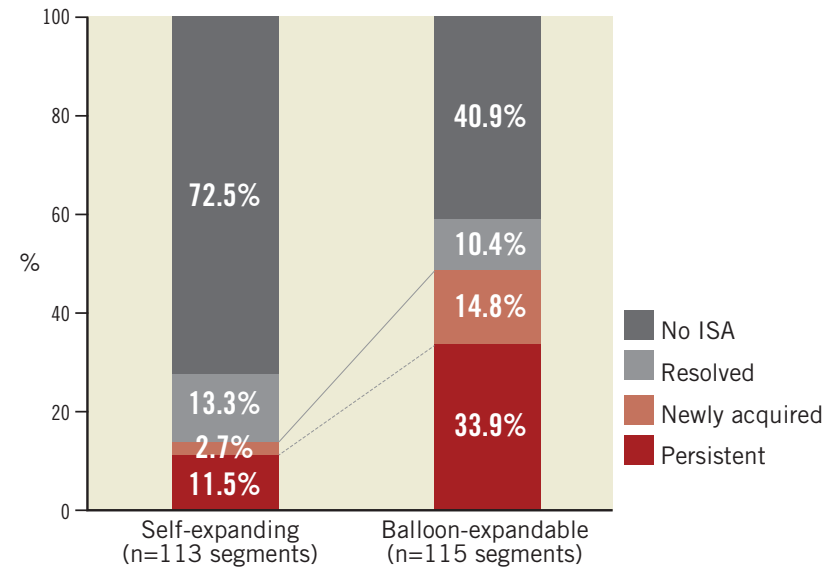

Figure 5. Summary of ISA changes in three days. In sequential assessment, resolved ISA was observed similarly in the self-expanding stents and the balloon-expandable stents $(p=0.51)$. The rate of persistent and newly acquired ISA in self-expanding stents was significantly less than in balloon-expandable stents (persistent: $p<0.001$; newly acquired: $p=0.001$ ). As a result, ISA was still present at three days in $14.2 \%$ of self-expanding stent segments and $48.7 \%$ of balloon-expandable stent segments. ISA: incomplete stent apposition

\section{THE CHANGE OF ISA IN SEGMENTAL ANALYSIS}

In the current sub-analysis of the APPOSITION II study, the additional matched segment-level analysis demonstrated the considerable change of ISA in the early phase after pPCI and the difference in temporal ISA change between self-expanding and balloonexpandable stents. ISA is a localised phenomenon in a stented

Table 4. Mechanisms of resolved, persistent and newly acquired ISA.

\begin{tabular}{|c|c|c|c|}
\hline & $\begin{array}{c}\text { Self- } \\
\text { expanding } \\
n=113\end{array}$ & $\begin{array}{c}\text { Balloon- } \\
\text { expandable } \\
n=115\end{array}$ & $p$-value \\
\hline \multicolumn{4}{|l|}{ Resolved ISA } \\
\hline Stent enlargement, $\mathrm{n}(\%)$ & $11(9.7)$ & $0(0.0)$ & $<0.001$ \\
\hline Tissue formation, $\mathrm{n}(\%)$ & $4(3.5)$ & $12(10.4)$ & 0.07 \\
\hline \multicolumn{4}{|c|}{ Persistent ISA with decreasing ISA volume } \\
\hline Stent enlargement, $\mathrm{n}(\%)$ & $6(5.3)$ & $0(0.0)$ & 0.01 \\
\hline Tissue formation, $\mathrm{n}(\%)$ & $2(1.8)$ & $13(11.3)$ & 0.01 \\
\hline \multicolumn{4}{|c|}{ Persistent ISA with increasing ISA volume } \\
\hline Tissue resorption, $\mathrm{n}(\%)$ & $2(1.8)$ & $11(9.6)$ & 0.02 \\
\hline Vasorelaxation, n (\%) & $3(2.7)$ & $9(7.8)$ & 0.14 \\
\hline $\begin{array}{l}\text { Vasorelaxation and stent } \\
\text { recoil, } \mathrm{n}(\%)\end{array}$ & $0(0.0)$ & $4(3.5)$ & 0.12 \\
\hline Stent recoil, n (\%) & $0(0.0)$ & $2(1.7)$ & 0.50 \\
\hline \multicolumn{4}{|l|}{ Newly acquired ISA } \\
\hline Tissue resorption, n (\%) & $3(2.7)$ & $7(6.1)$ & 0.33 \\
\hline Vasorelaxation, n (\%) & $0(0.0)$ & $5(4.3)$ & 0.06 \\
\hline $\begin{array}{l}\text { Vasorelaxation and stent } \\
\text { recoil, } \mathrm{n}(\%)\end{array}$ & $0(0.0)$ & $2(1.7)$ & 0.50 \\
\hline Stent recoil, n (\%) & $0(0.0)$ & $3(2.6)$ & 0.25 \\
\hline
\end{tabular}

segment, with an average length of $2.0 \mathrm{~mm}$ according to the previous literature 5 . Therefore, it is important to match the regions with ISA at different time points in order to assess the temporal changes. A strut-by-strut matching at two time points is ideal; however, this type of analysis is practically impossible to perform due to the rotation of the catheter and limited longitudinal resolution. As a pragmatic approach, segmental level matching using fiduciary landmarks was performed in the current analysis. In addition, foldout views based on frame-by-frame analysis were created to depict the clustering and spread distribution of ISA (Figure 4). In self-expanding stents, ISA had almost uniformly disappeared at three days. In balloon-expandable stents, there was some diversity in ISA distribution, suggesting that there was an influence of mechanical and locoregional factors on ISA.

\section{WORSENING OF ISA WITH VASORELAXATION, STENT RECOIL AND TISSUE RESORPTION IN A STEMI POPULATION}

To the best of our knowledge, this is the first OCT report demonstrating the contribution of vasorelaxation to the worsening of ISA three days after STEMI. The self-expanding device expands to its unconstrained size and takes advantage of the vasorelaxation to maintain the contact between struts and the luminal border of the vessel wall. In balloon-expandable stents, the stent dimensions remain the same or get smaller. Therefore, it is critical to select the proper size of stent and to try to anticipate the vessel dimension without vasoconstriction. Alternatively, it is important to eliminate the vasoconstriction as much as possible by administering nitrate before sizing of the vessels and selection of the stent size.

The other novel finding is that the "early" stent recoil (within three days after the procedure) of balloon-expandable stents is one of the aetiologies for the worsening of ISA. There was an average reduction of stent area by $0.11 \pm 0.66 \mathrm{~mm}^{2}$ at three days after implantation of balloon-expandable stents. This could be the result of the inherent recoil of the metallic structure rather than forced constriction by the surrounding tissue, since the reference vessels become more vasorelaxed during the first three days. It would be a technical challenge for a manufacturer to reduce the amount of "early" recoil of balloon-expandable stents.

\section{MALAPPOSED STRUTS AT THREE DAYS AFTER PPCI}

Foin et al showed that malapposed struts with maximum ISA detachment distance (the distance between the adluminal strut edge and vessel wall minus strut and polymer thickness) of $>300$ $\mu \mathrm{m}$ had a likelihood of delayed healing with drug-eluting stents (DES) in the setting of stable angina ${ }^{11}$. Gutiérrez-Chico et al showed that the ISA distance (the distance between the adluminal strut edge and vessel wall) of $<270 \mu \mathrm{m}$ was likely to be again apposed at nine months after DES implantation in the setting of stable angina ${ }^{5}$. In the current analysis of a STEMI population, the post-procedural malapposed struts with ISA detachment distance of $>250 \mu \mathrm{m}$ in self-expanding stents and $>200 \mu \mathrm{m}$ in balloonexpandable stents remained malapposed at three days. A serial OCT examination at long-term follow-up is warranted to create 
a threshold value for resolution or persistence of malapposition in the setting of STEMI, which could be helpful to establish the criterion of minimal ISA detachment distance which requires mechanical corrections of acute ISA by post-dilatation.

\section{Limitations}

This is a post hoc analysis and the population is too small to evaluate the clinical prognostic outcome of ISA. In addition, the influence of acute ISA or temporal ISA change during the first three days on the stent healing at follow-up was unclear since the current study did not have a serial OCT examination at long-term follow-up. The APPOSITION V study will evaluate whether the superior apposition of the STENTYS stent results in at least non-inferior outcome to a balloon-expandable stent ${ }^{19}$. The performance rate of post-dilatation was significantly different between self-expanding stents and balloon-expandable stents. These differences might influence the results of the ISA rate in the post-procedural phase, already reported in the original paper of APPOSITION II. The extent of ISA rather than its mere existence could be the underlying factor as a predictor of thrombosis. Other factors may also play a more relevant role in the risk of early thrombosis.

\section{Conclusion}

Three days after pPCI, tissue resorption and vasorelaxation were biological factors associated with new appearance of ISA while "early" recoil of balloon-expandable stents was a mechanical factor. Both persistent ISA and newly acquired ISA occurred less frequently in self-expanding stents, resulting in a lower number of ISA segments when compared to balloon-expandable stents.

\section{Impact on daily practice}

In the setting of STEMI, ISA is frequently observed and can be resolved or worsen shortly after pPCI due to several factors correlated with changes of vessel conditions and device performance. The current analysis demonstrated that vasodilatation and dissection were the main contributors to newly acquired ISA, and stent recoil was an important limitation in balloonexpandable stents. The post-procedural ISA detachment distance assessed by OCT could indicate remaining malapposed struts three days after pPCI. Taking into account these acute changes after pPCI, operators should decide on mechanical correction of post-procedural ISA by post-dilatation.

\section{Guest Editor}

This paper was guest edited by Fernando Alfonso, MD; Cardiac Department, Hospital Universitario de la Princesa, IIS-IP Universidad Autonoma de Madrid, Madrid, Spain.

\section{Acknowledgements}

The authors thank J.L. Gutiérrez-Chico for his interpretation of the methodology of the current substudy.

\section{Conflict of interest statement}

B. Witzenbichler received site reimbursement from STENTYS SA for participation in the APPOSITION II study. C. Spaulding is a member of the scientific advisory board for Medpass, Abiomed and Medtronic, has received speaker's honoraria from AstraZeneca, Eli Lilly, Daiichi Sankyo, Servier and Cordis, and has received research grants from Biosensors and Boston Scientific. R. Spaargaren is an employee of STENTYS SA. D. Capodanno has received speaker's honoraria from AstraZeneca, Boston Scientific, and Eli Lilly. RJ.M. van Geuns has received honoraria as a member of the speaker's board from STENTYS SA, Boston Scientific and Abbott Vascular. P.W. Serruys is a member of the Advisory Board for Abbott Vascular. Y. Onuma is a member of the Advisory Board for Abbott Vascular. The other authors have no conflicts of interest to declare. The Guest Editor has no conflicts of interest to declare.

\section{References}

1. Keeley EC, Boura JA, Grines CL. Primary angioplasty versus intravenous thrombolytic therapy for acute myocardial infarction: a quantitative review of 23 randomised trials. Lancet. 2003;361:13-20.

2. Adlbrecht C, Bonderman D, Plass C, Jakowitsch J, Beran G, Sperker W, Siostrzonek P, Glogar D, Maurer G, Lang IM. Active endothelin is an important vasoconstrictor in acute coronary thrombi. Thromb Haemost. 2007;97:642-9.

3. Di Stefano R, Di Bello V, Barsotti MC, Grigoratos C, Armani C, Dell'Omodarme M, Carpi A, Balbarini A. Inflammatory markers and cardiac function in acute coronary syndrome: difference in ST-segment elevation myocardial infarction (STEMI) and in non-STEMI models. Biomed Pharmacother. 2009;63:773-80.

4. van Werkum JW, Heestermans AA, Zomer AC, Kelder JC, Suttorp MJ, Rensing BJ, Koolen JJ, Brueren BR, Dambrink JH, Hautvast RW, Verheugt FW, ten Berg JM. Predictors of coronary stent thrombosis: the Dutch Stent Thrombosis Registry. J Am Coll Cardiol. 2009;53:1399-409.

5. Gutierrez-Chico JL, Wykrzykowska J, Nuesch E, van Geuns RJ, Koch KT, Koolen JJ, di Mario C, Windecker S, van Es GA, Gobbens P, Jüni P, Regar E, Serruys PW. Vascular tissue reaction to acute malapposition in human coronary arteries: sequential assessment with optical coherence tomography. Circ Cardiovasc Interv. 2012;5:20-9, S1-8.

6. Im E, Kim BK, Ko YG, Shin DH, Kim JS, Choi D, Jang Y, Hong MK. Incidences, predictors, and clinical outcomes of acute and late stent malapposition detected by optical coherence tomography after drug-eluting stent implantation. Circ Cardiovasc Interv. 2014;7:88-96.

7. van Geuns RJ, Tamburino C, Fajadet J, Vrolix M, Witzenbichler B, Eeckhout E, Spaulding C, Reczuch K, La Manna A, Spaargaren R, Garcia-Garcia HM, Regar E, Capodanno D, Van Langenhove G, Verheye S. Self-expanding versus balloon-expandable stents in acute myocardial infarction: results from the APPOSITION II study: self-expanding stents in ST-segment elevation myocardial infarction. JACC Cardiovasc Interv. 2012;5:1209-19. 
8. Serruys PW, Kay IP, Disco C, Deshpande NV, de Feyter PJ. Periprocedural quantitative coronary angiography after PalmazSchatz stent implantation predicts the restenosis rate at six months: results of a meta-analysis of the BElgian NEtherlands Stent study (BENESTENT) I, BENESTENT II pilot, BENESTENT II and MUSIC trials. Multicenter Ultrasound Stent In Coronaries. $J$ Am Coll Cardiol. 1999;34:1067-74.

9. Maier W, Windecker S, Kung A, Lutolf R, Eberli FR, Meier B, Hess OM. Exercise-induced coronary artery vasodilation is not impaired by stent placement. Circulation. 2002;105:2373-7.

10. Onuma Y, Thuesen L, van Geuns RJ, van der Ent M, Desch S, Fajadet J, Christiansen E, Smits P, Holm NR, Regar E, van Mieghem N, Borovicanin V, Paunovic D, Senshu K, van Es GA, Muramatsu T, Lee IS, Schuler G, Zijlstra F, Garcia-Garcia HM, Serruys PW; TROFI Investigators. Randomized study to assess the effect of thrombus aspiration on flow area in patients with ST-elevation myocardial infarction: an optical frequency domain imaging study--TROFI trial. Eur Heart J. 2013;34:1050-60.

11. Foin N, Gutierrez-Chico JL, Nakatani S, Torii R, Bourantas CV, Sen S, Nijjer S, Petraco R, Kousera C, Ghione M, Onuma Y, Garcia-Garcia HM, Francis DP, Wong P, Di Mario C, Davies JE, Serruys PW. Incomplete stent apposition causes high shear flow disturbances and delay in neointimal coverage as a function of strut to wall detachment distance: implications for the management of incomplete stent apposition. Circ Cardiovasc Interv. 2014;7:180-9.

12. Onuma Y, Serruys P, den Heijer P, Joesoef KS, Duckers H, Regar E, Kukreja N, Tanimoto S, Garcia-Garcia HM, van Beusekom H, van der Giessen W, Nishide T. MAHOROBA, firstin-man study: 6-month results of a biodegradable polymer sustained release tacrolimus-eluting stent in de novo coronary stenoses. Eur Heart J. 2009;30:1477-85.

13. Gutierrez-Chico JL, van Geuns RJ, Regar E, van der Giessen WJ, Kelbaek H, Saunamaki K, Escaned J, Gonzalo N, di Mario C, Borgia F, Nuesch E, Garcia-Garcia HM, Silber S, Windecker S, Serruys PW. Tissue coverage of a hydrophilic polymer-coated zotarolimus-eluting stent vs. a fluoropolymer-coated everolimus-eluting stent at 13-month follow-up: an optical coherence tomography substudy from the RESOLUTE all comers trial. Eur Heart J. 2011;32:2454-63.

14. Gutierrez-Chico JL, Radu MD, Diletti R, Sheehy A, Kossuth MB, Oberhauser JP, Glauser T, Harrington J, Rapoza RJ, Onuma Y, Serruys PW. Spatial distribution and temporal evolution of scattering centers by optical coherence tomography in the poly(1lactide) backbone of a bioresorbable vascular scaffold. Circ J. 2012;76:342-50.
15. Orii M, Kubo T, Tanaka A, Kitabata H, Ino Y, Shiono Y, Shimamura K, Aoki H, Ohta S, Ozaki Y, Ishibashi K, Yamano T, Tanimoto T, Yamaguchi T, Hirata K, Imanishi T, Akasaka T. Interscan reproducibility of geometric coronary artery measurements using frequency-domain optical coherence tomography. Int Heart J. 2013;54:64-7.

16. Gonzalo N, Garcia-Garcia HM, Serruys PW, Commissaris KH, Bezerra H, Gobbens P, Costa M, Regar E. Reproducibility of quantitative optical coherence tomography for stent analysis. EuroIntervention. 2009;5:224-32.

17. Tanimoto S, Rodriguez-Granillo G, Barlis P, de Winter S, Bruining N, Hamers R, Knappen M, Verheye S, Serruys PW, Regar E. A novel approach for quantitative analysis of intracoronary optical coherence tomography: high inter-observer agreement with computer-assisted contour detection. Catheter Cardiovasc Interv. 2008;72:228-35.

18. Jamil Z, Tearney G, Bruining N, Sihan K, van Soest G, Ligthart J, van Domburg R, Bouma B, Regar E. Interstudy reproducibility of the second generation, Fourier domain optical coherence tomography in patients with coronary artery disease and comparison with intravascular ultrasound: a study applying automated contour detection. Int J Cardiovasc Imaging. 2013;29: $39-51$.

19. Grundeken MJ, Lu H, Mehran R, Cutlip DE, Leon MB, Yeung A, Koch KT, Montalescot G, van Geuns RJ, Spaargaren R, Buchbinder M. APPOSITION V: STENTYS coronary stent system clinical trial in subjects with ST-segment elevation myocardial infarction--rationale and design. Am Heart J. 2014;168:652-60.

20. Sianos G, Papafaklis MI, Daemen J, Vaina S, van Mieghem CA, van Domburg RT, Michalis LK, Serruys PW. Angiographic stent thrombosis after routine use of drug-eluting stents in ST-segment elevation myocardial infarction: the importance of thrombus burden. J Am Coll Cardiol. 2007;50:573-83.

\section{Supplementary data}

Online Appendix. Methods.

Online Table 1. Baseline clinical and procedural characteristics.

Online Table 2. Differences in OCT variables between resolved and persistent ISA in self-expanding and balloon-expandable stents.

Online Table 3. Baseline and follow-up quantitative coronary analysis.

Online Figure 1. Mechanisms of ISA changes.

The supplementary data are published online at: http://www.pcronline.com/ eurointervention/91st_issue/179 


\section{Supplementary data}

\section{Online Appendix. Methods ANGIOGRAPHIC ASSESSMENT}

Quantitative coronary angiography (QCA) was performed using the CAAS 5 analysis system (Pie Medical BV, Maastricht, The Netherlands). In each patient, the following QCA parameters were measured in the stented segment and the peri-stent segments (defined by a length $5 \mathrm{~mm}$ proximal and distal to the stent edge): minimal lumen diameter (MLD), reference diameter obtained by an interpolated method, and percentage diameter stenosis (\%DS). For the assessment of vasoconstriction/relaxation, the mean lumen diameter of the remote distal segment ( 5 to $20 \mathrm{~mm}$ distal to the stented segment) was measured using QCA 9 . Intracoronary thrombus was angiographically identified and scored in five grades as previously described. Thrombus grade was assessed after flow achievement with crossing of a guidewire ${ }^{20}$.

\section{QUANTITATIVE ANALYSIS ON OCT}

The OCT measurements were performed with QCU-CMS software (Medis medical imaging systems bv, Leiden, The Netherlands) by analysts who were blinded to patient and procedural information. The cross-sectional areas of stent, lumen, prolapse and isolated intraluminal defect were measured at $1 \mathrm{~mm}$ intervals $\mathrm{s}^{7,10}$. The prolapse area was defined as the convex-shaped area of tissue protrusion between adjacent stent struts towards the lumen, without disruption of the continuity of the luminal vessel surface. Isolated intraluminal defect refers to a fixed structure separated from the vessel wall seen in the analysed cross-section and probably attached to the vessel wall at a proximal or distal site in a different cross-section.

Frames were excluded from the analysis if there were overlapping struts, or if there was a non-uniform rotational distortion, and if the struts and vessel wall could not be visualised due to insufficient blood clearance or an inadequately flushed OCT catheter.
Online Table 1. Baseline clinical and procedural characteristics.

\begin{tabular}{|c|c|c|c|}
\hline & $\begin{array}{c}\text { Self- } \\
\text { expanding } \\
(n=35)\end{array}$ & $\begin{array}{l}\text { Balloon- } \\
\text { expandable } \\
(n=34)\end{array}$ & $p$-value \\
\hline \multicolumn{4}{|l|}{ Baseline clinical characteristics } \\
\hline Age, years (mean $\pm S D$ ) & $61.1 \pm 12.8$ & $59.0 \pm 11.3$ & 0.49 \\
\hline Male, n (\%) & $30(85.7)$ & $28(82.4)$ & 0.70 \\
\hline Diabetes mellitus, $n(\%)$ & $7(20.0)$ & $4(11.8)$ & 0.35 \\
\hline Hypertension, n (\%) & $15(42.9)$ & $18(52.9)$ & 0.40 \\
\hline Hyperlipidaemia, n (\%) & $16(45.7)$ & $16(47.1)$ & 0.91 \\
\hline Current smoker, $\mathrm{n}(\%)$ & $19(54.3)$ & $25(73.5)$ & 0.10 \\
\hline Prior PCl, n (\%) & $0(0.0)$ & $0(0.0)$ & \\
\hline Prior CABG, $n(\%)$ & $0(0.0)$ & $0(0.0)$ & \\
\hline Prior Ml, n (\%) & $0(0.0)$ & $0(0.0)$ & \\
\hline Symptoms onset to $\mathrm{PCl}$, hrs & $2.0[1.5-4.0]$ & $3.0[2.0-4.0]$ & 0.29 \\
\hline Symptoms onset to $\mathrm{PCl}<3$ hrs, $\mathrm{n}$ (\%) & $24(68.6)$ & $19(55.9)$ & 0.35 \\
\hline Symptoms onset to $\mathrm{PCl}>6$ hrs, $\mathrm{n}$ (\%) & $3(8.6)$ & $5(14.7)$ & 0.40 \\
\hline \multicolumn{4}{|l|}{ Procedural characteristics } \\
\hline $\mathrm{RCA}, \mathrm{n}(\%)$ & $14(40.0)$ & $18(52.9)$ & 0.49 \\
\hline$L A D, n(\%)$ & $16(45.7)$ & $11(32.4)$ & \\
\hline LCX, n (\%) & $5(14.3)$ & $5(14.7)$ & \\
\hline Initial TIMI flow grade 0/1, n (\%) & $22(62.9)$ & $18(52.9)$ & 0.40 \\
\hline Thrombus grade 4, n (\%) & $15(42.9)$ & $19(55.9)$ & 0.20 \\
\hline Thrombus aspiration, $n$ (\%) & $25(71.4)$ & 29 (85.3) & 0.16 \\
\hline Predilatation, n (\%) & $20(57.1)$ & 14 (41.2) & 0.19 \\
\hline Post-dilatation, n (\%) & $22(62.9)$ & $8(23.5)$ & 0.001 \\
\hline Post TIMI flow grade 0/1, n (\%) & $0(0.0)$ & $0(0.0)$ & 0.40 \\
\hline
\end{tabular}


Online Table 2. Differences in OCT variables between resolved and persistent ISA in self-expanding and balloon-expandable stents.

\begin{tabular}{|c|c|c|c|c|c|c|}
\hline & \multicolumn{2}{|c|}{ Self-expanding } & \multirow{2}{*}{$p$-value } & \multicolumn{2}{|c|}{ Balloon-expandable } & \multirow{2}{*}{$p$-value } \\
\hline & Resolved ISA & Persistent ISA & & Resolved ISA & Persistent ISA & \\
\hline No. of segments & 15 & 13 & & 12 & 39 & \\
\hline \multicolumn{7}{|c|}{ OCT qualitative analysis post procedure } \\
\hline Located at stent edge, $\mathrm{n}(\%)$ & $4(26.7)$ & $6(46.2)$ & 0.29 & $3(25.0)$ & $11(28.2)$ & 0.83 \\
\hline Located at culprit lesions, n (\%) & $6(40.0)$ & $2(15.4)$ & 0.15 & $4(33.3)$ & $17(43.6)$ & 0.53 \\
\hline Intra-stent dissection, n (\%) & $4(26.7)$ & $5(38.5)$ & 0.51 & $4(33.3)$ & $20(51.3)$ & 0.28 \\
\hline \multicolumn{7}{|c|}{ OCT quantitative analysis post procedure } \\
\hline Max ISA detachment distance, $\mu \mathrm{m}$ & $178[78-363]$ & $105[90-162]$ & 0.06 & $105[90-162]$ & 237 [134-363] & 0.01 \\
\hline Max ISA area, $\mathrm{mm}^{2}$ & $0.24[0.16-0.41]$ & $0.45[0.34-0.69]$ & 0.08 & $0.19[0.15-0.30]$ & $0.53[0.25-1.55]$ & 0.10 \\
\hline ISA volume, $\mathrm{mm}^{3}$ & $0.15[0.08-0.39]$ & $0.29[0.17-0.53]$ & 0.22 & $0.13[0.09-0.20]$ & $0.43[0.16-2.36]$ & 0.10 \\
\hline Mean stent area, $\mathrm{mm}^{2}$ & $8.26 \pm 2.65$ & $6.87 \pm 2.23$ & 0.15 & $9.81 \pm 2.08$ & $8.76 \pm 2.16$ & 0.16 \\
\hline Mean lumen area, $\mathrm{mm}^{2}$ & $8.88 \pm 2.53$ & $7.79 \pm 2.41$ & 0.25 & $9.72 \pm 1.93$ & $9.13 \pm 2.38$ & 0.43 \\
\hline Mean protrusion area, $\mathrm{mm}^{2}$ & $0.02[0.00-0.24]$ & $0.04[0.01-0.07]$ & 0.99 & $0.18[0.12-0.45]$ & $0.19[0.09-0.36]$ & 0.96 \\
\hline Minimum stent area (MSA), $\mathrm{mm}^{2}$ & $7.17 \pm 2.28$ & $5.75 \pm 2.11$ & 0.13 & $9.30 \pm 2.11$ & $8.19 \pm 2.09$ & 0.11 \\
\hline MSA $<5.0 \mathrm{~mm}^{2}, \mathrm{n}(\%)$ & $4(26.7)$ & $3(23.1)$ & 0.83 & $0(0.0)$ & $2(5.1)$ & 1.00 \\
\hline Eccentricity index at MSA & $0.86[0.86-0.92]$ & $0.87[0.84-0.92]$ & 0.65 & 0.93 [0.92-0.95] & $0.92[0.86-0.95]$ & 0.22 \\
\hline$\%$ Area stenosis (AS), \% & $13.3[5.9-19.7]$ & 26.3 [9.3-30.5] & 0.07 & $4.6[-1.0-6.0]$ & 5.8 [-1.6-9.3] & 0.67 \\
\hline$\%$ AS $>20 \%, n(\%)$ & $4(26.7)$ & $8(61.5)$ & 0.07 & $0(0.0)$ & $2(5.1)$ & 1.00 \\
\hline
\end{tabular}

Online Table 3. Baseline and follow-up quantitative coronary analysis.

\begin{tabular}{|c|c|c|c|}
\hline & $\begin{array}{c}\text { Self- } \\
\text { expanding } \\
(n=35)\end{array}$ & $\begin{array}{l}\text { Balloon- } \\
\text { expandable } \\
(n=34)\end{array}$ & $p$-value \\
\hline \multicolumn{4}{|l|}{ Pre procedure } \\
\hline Lesion length, mm & $18.5[10.6-24.7]$ & $17.7[15.5-22.5]$ & 0.85 \\
\hline $\mathrm{RVD}, \mathrm{mm}$ & $2.63 \pm 0.44$ & $2.80 \pm 0.54$ & 0.16 \\
\hline MLD, mm & $0.84 \pm 0.28$ & $0.95 \pm 0.30$ & 0.05 \\
\hline $\mathrm{DS}, \%$ & $66.3 \pm 12.8$ & $65.8 \pm 10.6$ & 0.65 \\
\hline Dmax, mm & $3.22 \pm 0.48$ & $3.41 \pm 0.68$ & 0.24 \\
\hline \multicolumn{4}{|l|}{ Post procedure } \\
\hline Stent length, mm & $19.2[18.1-24.4]$ & $20.3[16.8-22.6]$ & 0.89 \\
\hline $\mathrm{RVD}, \mathrm{mm}$ & $2.82 \pm 0.44$ & $3.12 \pm 0.39$ & $<0.01$ \\
\hline MLD, mm & $2.40 \pm 0.43$ & $2.74 \pm 0.40$ & $<0.01$ \\
\hline $\mathrm{DS}, \%$ & $15.2 \pm 6.82$ & $12.5 \pm 5.1$ & 0.07 \\
\hline Acute gain, mm & $1.56 \pm 0.42$ & $1.79 \pm 0.47$ & 0.02 \\
\hline Mean remote distal segment, mm & $2.25 \pm 0.50$ & $2.57 \pm 0.66$ & 0.04 \\
\hline \multicolumn{4}{|l|}{ Follow-up at 3 days } \\
\hline Stent length, mm & $19.2[18.1-24.1]$ & $20.0[16.5-22.1]$ & 0.83 \\
\hline $\mathrm{RVD}, \mathrm{mm}$ & $2.93 \pm 0.43$ & $3.05 \pm 0.36$ & 0.27 \\
\hline MLD, mm & $2.49 \pm 0.47$ & $2.69 \pm 0.40$ & 0.05 \\
\hline DS,\% & $14.9 \pm 7.96$ & $12.0 \pm 7.1$ & 0.06 \\
\hline Lumen loss, mm & $-0.10 \pm 0.25$ & $0.05 \pm 0.22$ & 0.02 \\
\hline Mean remote distal segment, mm & $2.33 \pm 0.46$ & $2.58 \pm 0.61$ & 0.03 \\
\hline Diff. remote distal segment, mm & $0.06[-0.02-0.14]$ & $0.00[-0.09-0.19]$ & 0.20 \\
\hline FUP/post remote distal segment & $1.02[0.99-1.06]$ & $1.00[0.95-1.08]$ & 0.20 \\
\hline $\begin{array}{l}\text { Vasorelaxation (FUP/post remote } \\
\text { distal segment >1.05), } n(\%)\end{array}$ & $11(32.4)$ & $11(31.4)$ & 1.00 \\
\hline
\end{tabular}




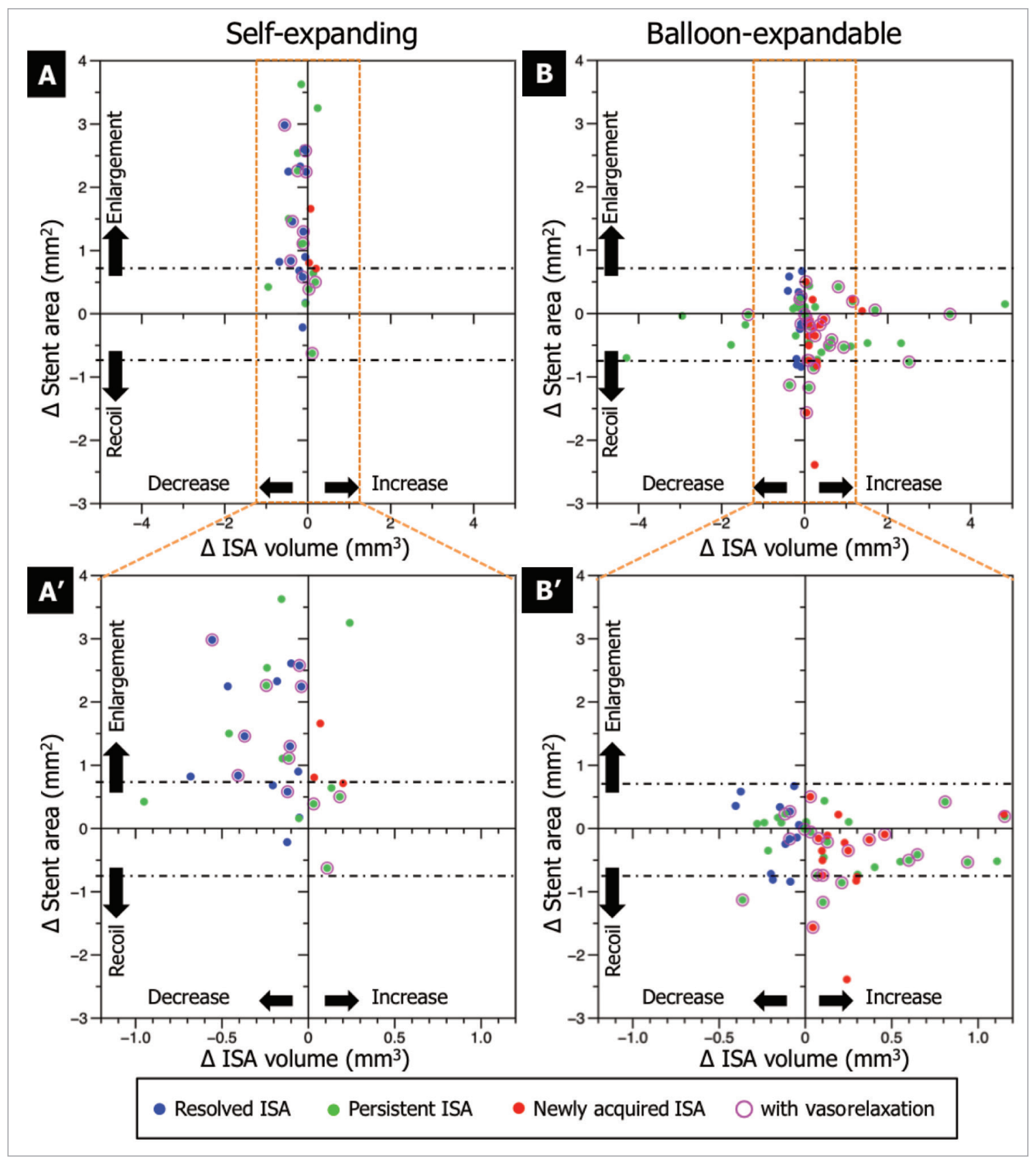

Online Figure 1. Mechanisms of ISA changes. The differences in stent area and ISA volume are shown in the scatter plot (self-expanding: A, A'; balloon-expandable: B and B'). The blue dots depict the resolved ISA, the green dots indicate the persistent ISA, and the pink dots identify the spots with the newly acquired ISA. The purple circle shows the segments with vasorelaxation. The black dash-dot line shows the border of stent enlargement and "early" recoil. The dots above the black dash-dot line show the segments with stent enlargement, the dots under the black dash-dot line show the segments with "early" stent recoil. The resolved ISA and persistent ISA with decreasing ISA volume caused by stent enlargement were observed only in self-expanding stents. The newly acquired ISA and persistent ISA with increasing ISA volume caused by "early" recoil were observed only in balloon-expandable stents. 